\title{
Estresse hídrico e condicionamento osmótico na qualidade fisiológica de sementes de Cnidoscolus juercifolius
}

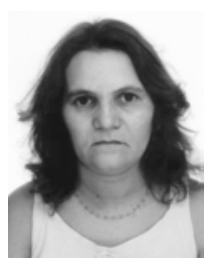

Lígia M. de M. Silva1 , Ivor B. de Aguiar², Deborah L. de Morais ${ }^{3}$ \& Ricardo A. Viégas ${ }^{4}$

1 DEF/CSTR/UFCG, CEP 58700-970.Patos, PB. Bolsista do CNPq, Fone: (83) 423-0696. E-mail: ligiamms@hotmail.com (Foto)
2 UNESP, CEP 57035-410. Jaboticabal, Bolsista do CNPq, Fone: (16) 3209-2668. E-mail: ivor@netsite.com.br
${ }^{3}$ DEF/CSTR/UFCG, Bolsista do CNPq (PIBIC), Fone: (83) 421-3397. E-mail: Deborahforest@hotmail.com
${ }^{4}$ DEF/UFCG. Fone: (83) 421-3397. E-mail: raviegas@uol.com.br

Protocolo 59 - 9/4/2003 - Aprovado em 24/9/2004

\begin{abstract}
Resumo: Objetivou-se, através deste trabalho, avaliar o efeito do potencial hídrico induzido por polietilenoglicol, e do condicionamento osmótico na qualidade fisiológica de sementes de Cnidosculus juercifolius (faveleira). Para simular o estresse hídrico, as sementes foram germinadas em substrato papel de filtro umedecido com soluções de nistatina a $0,2 \%$, sem (controle) ou com polietilenoglicol (PEG 6000), apresentando os seguintes valores de potencial osmótico: 0,0, $-0,1,-0,2,-0,3,-0,5,-0,7,-0,9,-1,1$ e $-1,3 \mathrm{MPa}$. O condicionamento osmótico consistiu em se colocar as sementes para embeberem, em solução de PEG 6000, com potencial osmótico ajustado para $-0,7 \mathrm{MPa}$, a $30{ }^{\circ} \mathrm{C}$, por $24,48,72$ e $96 \mathrm{~h}$. As sementes apresentaram bom desempenho germinativo até o potencial de $-0,3 \mathrm{MPa}$. A porcentagem de germinação foi afetada somente a partir de $-0,5 \mathrm{MPa}$, enquanto a velocidade de germinação foi reduzida já a partir de -0,3 MPa. O limite de tolerância ao estresse hídrico, simulado com o PEG-6000, foi observado entre $-0,7$ e - $0,9 \mathrm{MPa}$. O condicionamento osmótico das sementes de faveleira, em potencial de $-0,7 \mathrm{MPa}$, por $48 \mathrm{~h}$, foi benéfico para sementes com baixo vigor.
\end{abstract}

Palavras-chave: potencial osmótico, semente florestal, polietilenoglicol

\section{Water stress and osmotic conditioning on physiological quality of Cnidosculus juercifolius Pax \& K. Hoffam seeds}

\begin{abstract}
This work aimed to evaluate the effect of water potential as induced by polyetyleneglycol and of osmotic conditioning on the physiological quality of Cnidosculus juercifolius seeds. The water stress was carried out by germinating the seeds in substratum filter paper saturated with $0.2 \%$ nystaten solution without (control) or with polyethyleneglycol (PEG-6000) at the following osmotic potential values: $0.0,-0.1,-0.2,-0.3,-0.5,-0.7,-0.9,-1.1$ and $-1.3 \mathrm{MPa}$. For osmotic conditioning, the seeds were subjected to $-0.7 \mathrm{MPa}$ PEG-6000 solution, for $24,48,72$ and $96 \mathrm{~h}$, at $30{ }^{\circ} \mathrm{C}$. The seeds germinated well until the potential of $-0.3 \mathrm{MPa}$. The germination percentage reduced from $-0.5 \mathrm{MPa}$ while the speed of germination was reduced from $-0.3 \mathrm{MPa}$. The limit of tolerance to water stress in PEG-6000 of Cnidosculus juercifolius seeds is between -0.7 and -0.9 $\mathrm{MPa}$. The osmotic conditioning at-0.7 MPa for $48 \mathrm{~h}$ was beneficial for seeds with low vigor.
\end{abstract}

Key words: osmotic potential, forest seed, polyelthyleneglycol

\section{INTRODUÇÃO}

O processo de germinação das sementes constitui-se em uma fase crítica, influenciada por uma série de fatores em que se ressente da ausência de um conjunto de condições favoráveis para que possa ser realizado de forma satisfatória. Neste processo, a primeira etapa na seqüência de eventos que culminam com a retomada do crescimento do embrião é a embebição (Luca \& Reis, 1995). A absorção de água pela semente dá início a uma série de processos físicos, fisiológicos e bioquímicos que, na ausência de fatores limitantes, resultam na emergência da plântula (Popinigis, 1985).

A absorção de água pela semente ocorre em três fases distintas, em que a fase I é relativamente rápida e a absorção de 
água ocorre como conseqüência do potencial matricial dos vários tecidos das sementes e, desta forma, não depende da viabilidade da semente. Bioquimicamente, esta fase se caracteriza pelo início da oxidação das substâncias de reserva; na fase II a semente praticamente não absorve água mas mantém o nível de hidratação atingido, no final da fase I, o ponto em que ocorre o transporte dos metabólitos produzidos nos tecidos de reserva para os pontos de crescimento; enfim, na fase III ocorre grande absorção de água, sendo esta fase alcançada apenas por sementes viáveis e permeáveis. Neste estádio, o eixo embrionário já iniciou seu crescimento de maneira que as novas células, em processo de formação e crescimento, demandam significativa quantidade de água (Bewley \& Black, 1994).

A deficiência hídrica é o fator limitante de maior significância na sobrevivência e crescimento inicial de plantas (Blake, 1993). O estresse hídrico pode afetar a germinação provocando atraso no início do processo ou diminuição na germinabilidade final (Hardegree \& Emmerich, 1990). Potenciais muito baixos, especialmente no início da embebição, influenciam a absorção de água, inviabilizando a seqüência dos eventos germinativos (Bansal et al., 1980). Por outro lado, o excesso de umidade em geral provoca decréscimo na germinação, uma vez que impede a difusão do oxigênio e reduz todo o processo metabólico resultante (Borges \& Rena, 1993).

Uma das técnicas mais utilizadas para simular condições de baixa umidade no substrato tem sido o uso de soluções com diferentes potenciais osmóticos (Taylor \& Harman, 1990). O polietilenoglicol (PEG) por não penetrar nas células, não ser degradado e não causar toxidez, devido ao seu alto peso molecular (Hasegawa et al., 1984), tem sido utilizado com sucesso em trabalhos de pesquisa para simular os efeitos da deficiência hídrica nas plântulas.

Diversos estudos são realizados com a finalidade de se recuperar e manter o poder germinativo das sementes, além de reduzir o tempo entre a semeadura e a emergência das plântulas. Entre os tratamentos que se têm mostrado eficientes, o condicionamento osmótico é apontado como o mais promissor (Khan, 1992; Murray et al.,1992).

O condicionamento osmótico é uma técnica de embebição controlada das sementes, que permite a ocorrência de uma ativação fisiológica mas, por outro lado, impede a germinação. Sementes tratadas desta forma apresentam, freqüentemente, germinação mais rápida e uniforme, quando reidratadas (Bradford, 1986). Este efeito tem sido reproduzido satisfatoriamente em soluções, pelo acréscimo de agentes osmóticos orgânicos, como é o caso do polietilenoglicol (PEG 6000). Uma vez alcançado o estádio pré-germinativo ideal, as sementes de algumas espécies podem ser submetidas à secagem, até atingirem o teor de água inicial, e armazenadas até o momento de sua utilização ou imediatamente semeadas (Trigo et al., 1999).

A carência de informações sobre as espécies florestais tropicais tem dificultado a adoção de práticas conservacionistas ou de recuperação de áreas degradadas. Neste contexto, um dos problemas que ainda demandam muita informação, diz respeito à conservação de sementes, pois muitas espécies florestais tropicais apresentam sementes com curta longevidade dificultando sua utilização por períodos de tempo mais prolongados (Carpi et al., 1996). Pesquisas demonstrando a eficiência do condicionamento osmótico na recuperação ou manutenção do poder germinativo de sementes armazenadas, de algumas espécies, indicam ser esta uma alternativa viável (Bradford, 1986; Murray et al., 1992). Esta técnica, associada às condições ideais de armazenamento, pode contribuir para o melhor aproveitamento das sementes de espécies arbóreas tropicais (Barbedo et al., 1997).

Entre as espécies arbóreas tropicais, tal técnica já foi utilizada com sucesso para Miconia candolleana quaresminha (Borges et al.,1994), Esenbeckia leiocarpa guarantã (Córdoba et al., 1995), Cedrela fissilis - cedro-rosa (Barbedo et al., 1997), Dalbergia nigra - jacarandá-da-bahia (Borges \& Borges, 1996) e Adenanthera pavonina - orelha-dedragão (Fanti \& Perez, 1998).

Com o presente trabalho objetivou-se estudar o efeito do estresse hídrico e do condicionamento osmótico na qualidade fisiológica de sementes de faveleira (Cnidosculus juercifolius), espécie florestal endêmica do semi-árido nordestino.

\section{MATERIAL E MÉTODOS}

Este estudo foi conduzido no Laboratório de Sementes Florestais do Departamento de Produção Vegetal da Faculdade de Ciências Agrárias e Veterinárias da Universidade Estadual Paulista de Jaboticabal, SP.

\section{Estresse hídrico}

Para a realização deste experimento utilizaram-se sementes colhidas em agosto de 2000, na cidade de Patos, PB, e armazenadas durante 60 dias em câmara fria $\left(10^{\circ} \mathrm{C}\right.$ e $75 \%$ UR). Para prevenir a ocorrência de incidência de patógenos as sementes foram, antes de cada teste, imersas em solução de hipoclorito de sódio comercial, a 4\%, durante $10 \mathrm{~min}$ e em seguida lavadas com excesso de água destilada.

A deficiência hídrica crescente foi simulada com soluções de nistatina a $2 \%$, contendo concentrações de PEG-6000 necessárias à obtenção dos seguintes valores de potenciais hídricos: $0 ;-0,1,-0,2 ;-0,3 ;-0,5 ;-0,7 ;-0,9,-1,1$ e - $1,3 \mathrm{MPa}$, os quais foram calculados de acordo com os procedimentos descritos por Michel \& Kaufmann (1973). O controle experimental $(0 \mathrm{MPa})$, correspondeu à solução de nistatina a $2 \%$, sem a presença de PEG-6000. O substrato utilizado foi constituído de duas folhas de papel de filtro (previamente autoclavadas), acondicionadas em caixa de plástico transparente, com tampa $(12 \times 14 \times 12 \mathrm{~cm})$, umedecidas com as soluções de diferentes valores de potencial hídrico, de forma a não permitir alterações importantes nos valores dos potenciais hídricos estabelecidos; o substrato foi trocado diariamente e as sementes incubadas a $30^{\circ} \mathrm{C}$, durante 20 dias.

\section{Condicionamento osmótico}

Este experimento foi realizado com sementes colhidas em julho de 1999 (consideradas de baixo vigor) as quais foram armazenadas em câmara fria $\left(10^{\circ} \mathrm{C} \mathrm{e} 75 \% \mathrm{UR}\right)$, até a instalação do experimento, e com sementes colhidas em abril de 2001 (reconhecidas como de alto vigor) também submetidas aos 
mesmos procedimentos de armazenamento. O experimento foi conduzido em maio de 2001.

Para determinação da curva de embebição, as sementes foram postas para embeber em $15 \mathrm{~mL}$ de solução de PEG 6000 ou água destilada (controle experimental). Foram utilizadas três repetições. Após cada período de embebição determinou-se o teor de água das sementes, pelo método da estufa a $105 \pm 3{ }^{\circ} \mathrm{C}$ por $24 \mathrm{~h}$ (Brasil, 1992).

Para o estudo do efeito do condicionamento osmótico, as sementes foram colocadas em $30 \mathrm{~mL}$ de solução de PEG $6000 \mathrm{a}$ $-0,7 \mathrm{MPa}$ por $24,48,72$ e $96 \mathrm{~h}$. Após cada período de osmocondicionamento, elas foram lavadas superficialmente em água corrente, com a finalidade de eliminar o excesso de PEG, sendo imediatamente secadas com papel toalha; a seguir, as sementes foram colocadas para germinar em temperatura alternada de $20-35^{\circ} \mathrm{C}$, tendo como substrato vermiculita umedecida com solução de nistatina a $0,2 \%$. O teste de germinação teve duração de 15 dias e foi conduzido com cinco repetições de 20 sementes, em germinador tipo B.O.D. O fotoperíodo foi de $8 \mathrm{~h}$ e o período luminoso correspondeu à temperatura mais elevada. Considerou-se germinada a semente que apresentou raiz principal igual ou maior que um centímetro. Os cálculos de porcentagem, velocidade e freqüência relativa da germinação foram conduzidos segundo procedimentos listados por Labouriau \& Agudo (1987).

Para determinação da curva de embebição e osmocondicionamento das sementes, utilizou-se solução de PEG-6000 com potencial de - $0,7 \mathrm{MPa}$. As sementes foram acondicionadas em caixas de plástico transparente, com tampa, forradas com duas folhas de papel de filtro. As caixas foram fechadas, vedadas com fita adesiva e posteriormente acondicionadas em germinador, a $30^{\circ} \mathrm{C}$, com luz branca.

\section{Análises estatísticas}

O delineamento utilizado foi o inteiramente casualizado. Os dados obtidos foram submetidos às análises de variância e de regressão polinomial, enquanto os de porcentagem foram transformados em arcsen $\sqrt{P / 100}$ para efetuar a análise estatística sendo que nos gráficos são apresentados os dados originais.

\section{RESULTADOS E DISCUSSÃO}

\section{Estresse hídrico}

Os valores de porcentagem e velocidade de germinação ajustaram-se à equação de regressão quadrática (Figura 1).

Os valores máximos de porcentagem de germinação sob diferentes potenciais osmóticos foram verificados nos potenciais de $-0,1,-0,2$ e -0,3 MPa os quais não se mostraram diferentes estatisticamente do controle. Em concentração de PEG maior que -0,5 MPa ocorreu redução acentuada da percentagem de germinação até sua nulidade, em -0,9 $\mathrm{MPa}$. Uma redução acentuada na germinação com o aumento da concentração de PEG 6000 (-0,5 MPa) pode ser atribuída a decréscimos na quantidade de água absorvida pelas sementes, uma vez que o PEG-600 não produz efeitos tóxicos no metabolismo celular (Hasegawa et al., 1984).
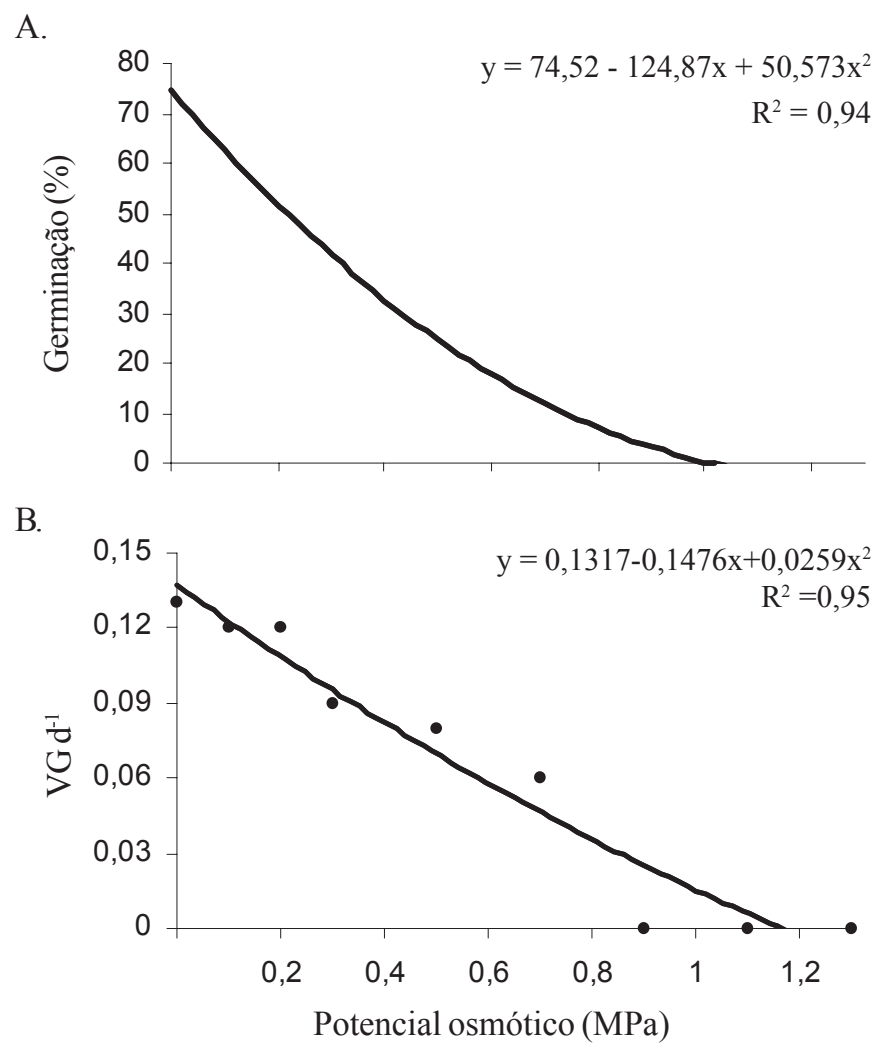

Figura 1. Porcentagem (A) e velocidade de germinação - VG (B) de sementes de Cnidosculus juercifolius submetidas a diferentes valores de potencial hídrico

Os baixos potenciais osmóticos $(-0,9$ a $-1,3 \mathrm{MPa})$ restringiram a absorção de água pela semente, inibindo completamente a germinação. O decréscimo observado na germinação das sementes com a redução do potencial osmótico, foi também verificado por Silva et al. (2001). Esses autores constataram que sementes de Bowdichia virgilioides (sucupira) apresentaram desempenho germinativo satisfatório até o potencial osmótico de $-0,3 \mathrm{MPa}$, mas uma redução significativa neste parâmetro ocorreu a partir de -0,5 MPa.

Para Bewley \& Black (1994) inibição na emergência da raiz principal decorrente de uma disponibilidade menor de água relaciona-se, freqüentemente, a reduções na atividade de algumas enzimas com prejuízo ao metabolismo geral das sementes. Segundo Caproni et al. (1993) diferentes espécies resistem a diferentes valores de potencial hídrico, ocorrendo diminuição drástica ou inibição total da emergência de plântulas. No presente estudo as sementes de faveleira germinaram satisfatoriamente até o potencial de $-0,7 \mathrm{MPa}$, indicando que o limite de tolerância desta espécie se situa entre -0,7 e -0,9 MPa.

Em comparação com outras espécies florestais, as sementes de faveleira apresentaram pequena tolerância ao estresse hídrico. Como exemplos, sementes de Leucaena leucocephala (leucena) germinaram em potencial hídrico de até -1,5 $\mathrm{MPa}$ (Cavalcante \& Perez, 1995); em sementes de Pterogyne nitens (amendoim-bravo) a germinação ocorreu em potencial hídrico de até -1,0 MPa, em solução de PEG, e de até -2,4 MPa quando as sementes foram submetidas a solução de manitol (Nassif \& Perez, 1997). 
No presente estudo apresentava-se a expectativa de que as sementes de faveleira, uma espécie endêmica da caatinga nordestina, germinassem em menores valores de potencial hídrico. Assim, é provável que este resultado esteja relacionado com o local de origem das sementes, as quais foram colhidas de árvores localizadas nas margens de uma barragem ou em locais de baixada. Segundo Moore \& Kidd (1982), as variações obtidas em diferentes potenciais osmóticos refletem a disponibilidade de umidade do local de origem das sementes, indicando diferenciação de espécie em ecótipos distintos. Borges et al. (1991) observaram que as sementes de jacarandáda-bahia germinaram em potenciais osmóticos mais elevados que as sementes de cedro-rosa. Os autores relacionaram este resultado com o local de origem das sementes, pois as de cedrorosa foram colhidas em locais de baixada e as de jacarandá-dabahia em áreas mais secas, como partes altas das elevações.

A velocidade de germinação das sementes de faveleira foi, comparativamente, mais afetada pelo estresse hídrico do que o foi a sua capacidade germinativa, uma vez que para o primeiro ocorreu redução significativa já a partir de $-0,3 \mathrm{MPa}$ (Figura 1A, B). Bewley \& Black (1994) relataram que o estresse hídrico provoca atraso na germinação das sementes e, como estas são bastante heterogêneas em suas respostas ao estresse hídrico, a germinação é distribuída no tempo e no espaço permitindo que, em condições naturais, as plântulas encontrem condições ambientais adequadas ao seu estabelecimento e desenvolvimento, resultados esses também verificados por outros autores. Cavalcante \& Perez (1995) obtiveram redução na velocidade de germinação de sementes de leucena a partir de $-0,3 \mathrm{MPa}$, enquanto a porcentagem de germinação só foi reduzida a partir de -0,6 MPa. Em sementes de Stryphnodendron polyplyllum (barbatimão), a velocidade de germinação foi reduzida a partir de $-0,1 \mathrm{MPa}$, enquanto a porcentagem de germinação o foi a partir de -0,5 MPa (Tambeline \& Perez, 1998).

Os polígonos de freqüência relativa da germinação foram polimodais para todos os tratamentos (Figura 2). Observa-se que o tempo médio e o primeiro dia com ocorrência de germinação foram deslocados para a direita, na medida em que o potencial hídrico foi reduzido. O número de sementes germinadas foi menor à medida que o potencial hídrico foi reduzido, o que revela que as sementes de faveleira distribuem a germinação ao longo do tempo sempre que as condições hídricas se tornam mais adversas, até que somente as sementes mais vigorosas germinam, como parece ter sido o caso do potencial de $-0,7 \mathrm{MPa}$, em que apenas $5 \%$ das sementes germinaram. Este comportamento germinativo, analisado através da freqüência relativa, foi também verificado em sementes de orelha-de-dragão (Fanti \& Perez, 1998) e de barbatimão (Tambeline \& Perez, 1998).

\section{Condicionamento osmótico}

Vê-se, através das curvas de embebição em água e em solução de PEG-6000, que as sementes de baixo e alto vigor apresentaram padrão semelhante de embebição e os resultados se ajustaram melhor à equação de regressão quadrática (Figura 3). Tanto a velocidade de embebição quanto o teor de água das sementes foram menores para as sementes embebidas em PEG6000 . As sementes de alto e baixo vigor em contato com PEG6000 atingiram, após $96 \mathrm{~h}$ de embebição, 27,9 e 29,3\% de água, respectivamente. Por outro lado, quando as sementes de alto e baixo vigor foram mantidas em contato com água destilada por $96 \mathrm{~h}$, os seus teores em água foram de 35,7 e $37,8 \%$,

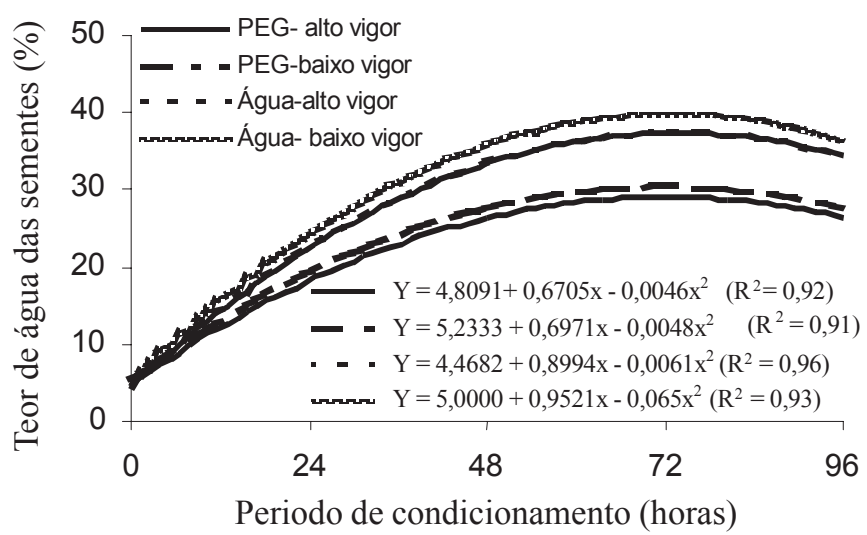

Figura 3. Curva de embebição de sementes de Cnidosculus juercifolius apresentando alto e baixo vigor, em água ou PEG-600
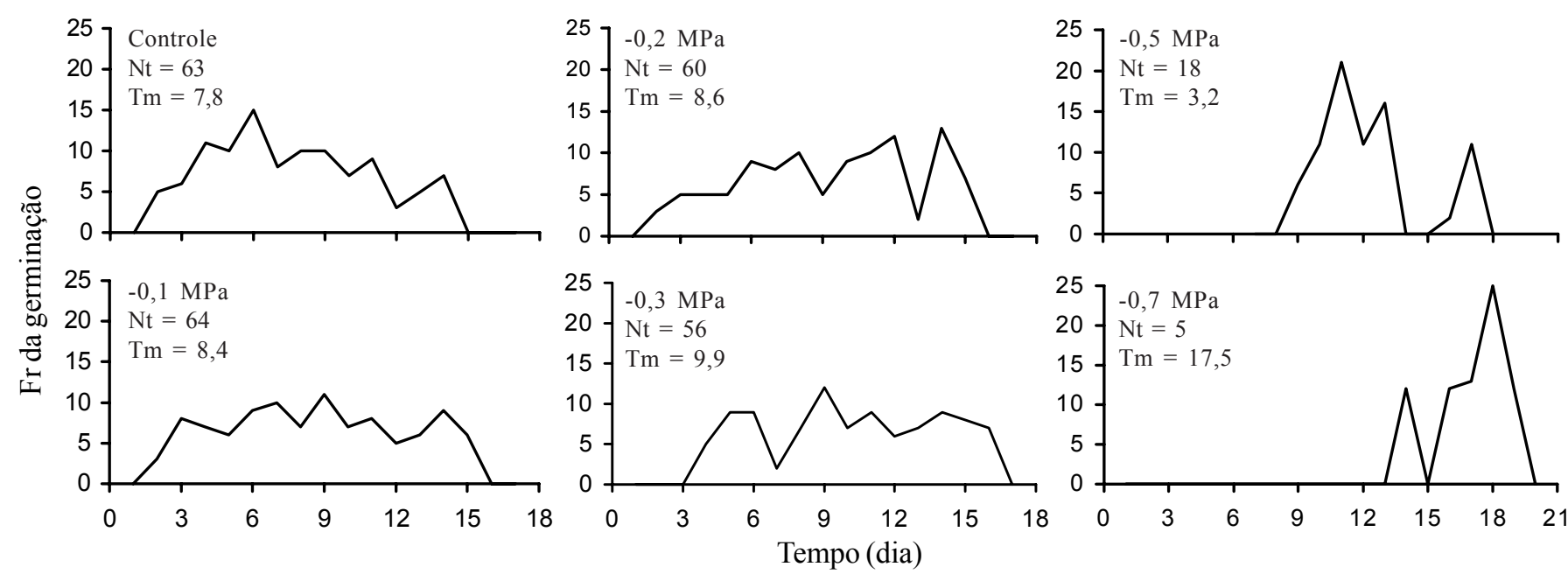

Nt - número total de sementes germinadas; Tm - tempo médio de germinação

Figura 2. Polígonos de freqüência relativa (Fr) da germinação de sementes de Cnidosculus juercifolius submetidas a diferentes potenciais hídricos. 
respectivamente, cujos resultados demonstram a eficiência do osmocondicionamento em restringir a absorção de água. Segundo Powell \& Mathews (1978), a velocidade com que a água penetra nos tecidos das sementes tem papel decisivo no sucesso da germinação. Quando a semente é colocada em contato com água pura a embebição é muito rápida podendo ocorrer danos ou injúrias em alguns tecidos. Para Armstrong \& McDonald (1992), os efeitos prejudiciais da rápida embebição das sementes podem ser decorrentes de alguns fatores, tais como: redução da integridade das membranas celulares; aumento da atividade de microrganismos ou, ainda, baixa disponibilidade de oxigênio.

O comportamento das sementes de faveleira está de acordo com o padrão estabelecido por Bewley \& Black (1994), em que o processo de embebição segue um padrão trifásico caracterizado por uma fase inicial de absorção rápida de água, seguida por uma fase estacionária, finalizando com novo aumento na taxa de absorção, que coincide com a protrusão da raiz principal. Em solução de PEG-6000 observou-se que o teor de água das sementes foi praticamente constante a partir de $48 \mathrm{~h}$ (Figura 3) devido ao fato de que as sementes tendem a atingir o equilíbrio entre o seu teor de água com o potencial osmótico, após este período.

As sementes de baixo vigor apresentaram leve aumento na absorção de água em relação às sementes de alto vigor. Isto pode significar menor seletividade nas membranas das sementes mais velhas, o que indica ocorrência de um estádio mais avançado de deterioração (Bewley \& Black, 1994). Observa-se, também, que sementes de alto e baixo vigor apresentaram, quando submetidas ao condicionamento osmótico, respostas diferenciadas quanto à porcentagem de germinação. Esses resultados comprovam observações feitas por Heydecker \& Coolbear (1977), de que lotes de sementes com qualidade fisiológica contrastante, respondem diferentemente ao condicionamento osmótico. Assim, as sementes de faveleira com alto vigor apresentaram redução consistente na porcentagem de germinação ( $81 \%$ após $96 \mathrm{~h}$ de embebição), quando submetidas ao condicionamento osmótico, em relação ao controle $(92 \%)$; ao contrário, o condicionamento osmótico tendeu a melhorar a germinação das sementes de baixo vigor, caso em que a porcentagem de germinação aumentou até $48 \mathrm{~h}$ de embebição, atingindo $63 \%$ e, em seguida, decresceu lentamente (Figura 4A).

Segundo Bradford (1986) a técnica do condicionamento osmótico tem sido um tratamento efetivo para aumentar o potencial de germinação e o vigor das sementes de lotes de baixa qualidade fisiológica.

Não houve diferença significativa para a velocidade de germinação das sementes de alto vigor, com relação ao controle e às osmocondicionadas, mas a velocidade de germinação das sementes osmocondicionadas, foi reduzida nas primeiras $24 \mathrm{~h}$ e voltou a aumentar a partir de $48 \mathrm{~h}$ (Figura 4B). Córdoba et al. (1995) verificaram que a alta viabilidade das sementes de Eucalyptus grandis (84,75\%), em relação a outros lotes, foi responsável pela falta de sensibilidade ao osmocondicionamento. $\mathrm{O}$ condicionamento osmótico por $48 \mathrm{~h}$ de sementes de faveleira de baixo vigor, promoveu aumento da velocidade de germinação quando comparada com as sementes

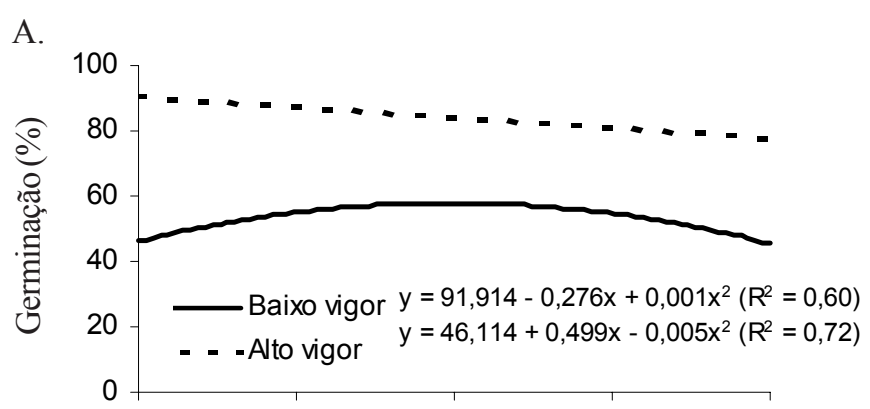

B.

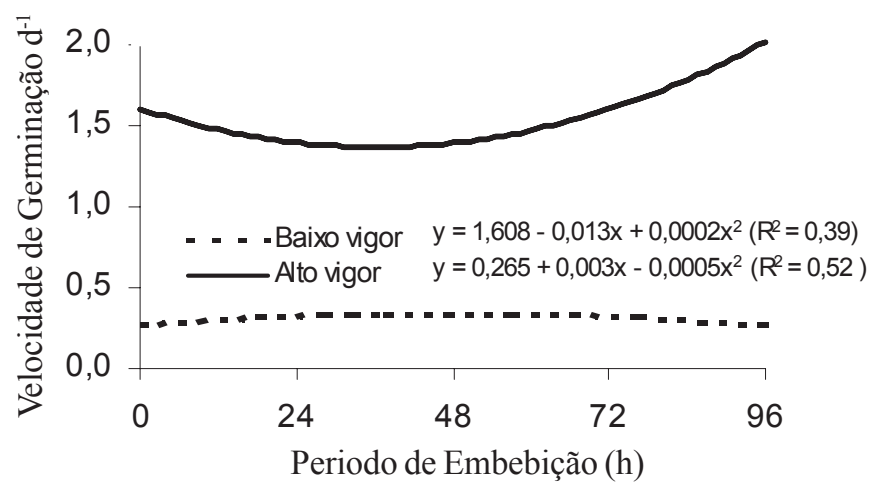

Figura 4. Porcentagem de germinação (A) e velocidade de germinação (B) de sementes de Cnidosculus juercifolius de alto e baixo vigor submetidas a diferentes períodos de condicionamento osmótico

não condicionadas (Figura 4B). Uma velocidade maior de germinação foi obtida após $48 \mathrm{~h}$ de embebição, decrescendo em seguida.

A diferença nos efeitos produzidos pelo condicionamento osmótico em sementes com níveis de vigor diferentes, reforça a conclusão de Powell (1998) de que as respostas das sementes submetidas ao osmocondicionamento são mais intensas para os lotes que iniciaram o processo de deterioração. Este revigoramento das sementes, obtido pelo condicionamento osmótico, seria causado por um "reparo" da estrutura das membranas celulares (Heydecker et al., 1975). Os autores consideraram que a principal vantagem do condicionamento das sementes é a maior velocidade de emergência das plântulas favorecendo, desta forma, maior tolerância das sementes às adversidades climáticas por ocasião da semeadura. Barbedo et al. (1997) constataram efeito imediato, favorecendo a germinação de sementes de cedro-rosa, sendo mais evidente no lote de qualidade intermediária. Em sementes de Eucalyptus citriodora, o condicionamento osmótico só beneficiou a emergência em sementes com potencial germinativo inferior a 70,75\% (Córdoba et al., 1995).

Há trabalhos demonstrando a eficiência do condicionamento osmótico na recuperação ou manutenção do poder germinativo de sementes de algumas espécies arbóreas, indicando uma alternativa para melhor aproveitamento das mesmas (Bradford, 1986; Murray et al., 1992). Entre as espécies arbóreas tropicais, essa técnica foi utilizada com sucesso para sementes de quaresminha (Borges et al.,1994), guarantã (Córdoba et al., 
1995), cedro-rosa (Carpi et al., 1996) e jacarandá-da-bahia (Borges \&Borges, 1996).

\section{CONCLUSÕES}

1. As sementes de Cnidosculus juercifolius apresentaram bom desempenho germinativo até o potencial de -0,3 MPa.

2. A porcentagem de germinação foi afetada a partir de $-0,5$ $\mathrm{MPa}$, enquanto sua velocidade foi reduzida a partir de $-0,3$ $\mathrm{MPa}$.

3. O limite de tolerância ao estresse hídrico simulado com o PEG-6000 situa-se entre -0,7 e -0,9 MPa.

4. O condicionamento osmótico de sementes em potencial de $-0,7$ MPa por $48 \mathrm{~h}$, foi benéfico para as sementes de baixo vigor.

\section{LITERATURA CITADA}

Armstrong, H.; Mcdonald, M.B. Effects of osmoconditioning on water uptake and electrical conductivity in soybean seeds. Seed Science and Technolology, Zurich, v.20, p.391400, 1992.

Bansal, R.P.; Bhati, P.R.; Sen, D.N. Differential specificity in water inhibition of Indian arid zone. Biologia Plantarum, Praha, v.22, p.327-331, 1980.

Barbedo, C.J.; Marcos Filho, J.; Novembre, A.D.L.C. Condicionamento osmótico e armazenamento de sementes de cedro-rosa (Cedrela fissilis Vell.). Revista Brasileira de Sementes, Brasília, v.19, n.2, p.355-361, 1997.

Bewley, J.D.; Black, M. Seeds: Physiology of development and germination. $2^{\mathrm{a}}$ ed. New York: Plenum Press, 1994. 445p.

Blake, T.J. Transplanting shock in white spruce: Effect of cold storage and root pruning on water relations and stomatal conditioning. Plant Physiology, Lancaster, v.57, p.210-216, 1993.

Borges E.E.L.; Borges, R.C.G. Modificações fisiológicas em sementes osmocondicionadas de jacarandá-da-bahia (Dalbergia nigra (Vell.) Fr. All). Revista Brasileira de Sementes, Brasília, v.20, n.2, p.147-154, 1996.

Borges, E.E.L.; Rena, A.B. Germinação de sementes. In: Aguiar, I.B.; Piña-Rodrigues, F.C.M.; Figliolia, M.B. Sementes florestais tropicais. Brasília: ABRATES, 1993.Cap.3, p. 133135 .

Borges, E.E.L.; Silva, L.F.; Borges, R.C. Avaliação do osmocondicionamento na germinação de sementes de quaresminha (Miconia candilleana Trian). Revista Brasileira de Sementes, Brasília, v.16, n.1, p.90-94, 1994.

Borges, E.E.L.; Vasconcelos, P.C.S.; Carvalho, D.V.; Borges, R.C.G. Estudos preliminares sobre o efeito do estresse hídrico na germinação de sementes de jacarandá-da-bahia (Dalbergia nigra) e cedro-rosa (Cedrella fissilis), Revista Brasileira de Sementes, Brasília, v.13, n.2, p.115-118, 1991.

Bradford, K.J. Manipulation of seed relations via osmotic priming to improve germination under stress conditions. Hortscience, Alexandria, v.21, n.5, p.1105-1112, 1986.

Brasil. Ministério da Agricultura e Reforma Agrária. Regras para análise de sementes. Brasília: SNAD/CLAV, 1992.365p.
Caproni, A.L.; Vieira, J.L.; Davide, A.C. Germinação de sementes de Eucalyptus grandis Hill ex. Maiden e Eucalyptus citriodora Hook, em dois tamanhos, submetidos a diferentes potenciais osmóticos. In: Congresso Florestal Panamericano, 1. Congresso Florestal Brasileiro, 7, 1993, Curitiba. Anais... São Paulo: SBS/ABEF, 1993, p.289-291.

Carpi, S.M.F.; Barbedo, C.J.; Marcos Filho, J. Condicionamento osmótico de sementes de Cedrela fissilis Vell. Revista Brasileira de Sementes, Brasília, v.18, n.2, p.271-275, 1996.

Cavalcante, A.M.B.; Perez, S.C.J.G.A. Efeitos dos estresses hídrico e salino sobre a germinação de sementes de Leucaena leucocephala (Lam.) de Wit. Pesquisa Agropecuária Brasileira, Brasília, v.30, n.2, p.281-289, 1995.

Córdoba, G.A.T.; Borges, E.E.L.; Borges, R.C.G.; Neves, J.C.L. Osmocondicionamento, secagem e armazenamento de sementes de Eucalyptus citriodora Hook e Eucalyptus grandis W. Hill. (ex. Maiden). Revista Brasileira de Sementes, Brasília, v.17, n.1, p.81-95, 1995.

Fanti, S.C.; Perez, S.C.J.G.A. Efeitos do estresse hídrico, salino e térmico no processo germinativo de sementes de Adenanthera pavonina L. Revista Brasileira de Sementes, Brasília, v.20, n.1, p.167-177, 1998.

Hardegree, S.P.; Emmerich, W.E. Effect of polyethylene glycol exclusion on the water potential of solution saturated filter paper. Plant Physiology, Lancaster, v.92, p.462-466, 1990.

Hasegawa, P.M.; Bressan, R.A.; Handa, S.; Handa, A.K. Cellular mechanisms of tolerance to water stress. Hortscience, Alexandria, v.19, n.3, p.371-377, 1984.

Heydecker, W.; Coolbear, P. Seed treatments for improve performance; survey and attempted prognosis. Seed Science and Technology, Zurich, v.5, p.353-425, 1977.

Heydecker, W.; Higgins, J.; Turner, Y.J. Invigoration of seeds? Seed Science and Technology, Zurich, v.3, n.3/4, p.821-881, 1975.

Khan, A.A. Preplant physiological seed conditioning. Horticutural Review, Edinburgh, v.13, p.131-181, 1992.

Labouriau, L.G.; Agudo, M. On the physiology of seeds germination in Salvia hispanica L. I. Temperature effects. Anais da Academia Brasileira de Ciências, Rio de Janeiro, v.59, n.1, p.37-56, 1987.

Luca, A.; Reis, M.S. Considerações sobre a influência do potencial hídrico e do condicionamento osmótico na qualidade fisiológica de sementes de soja. Informativo Abrates, Brasília, v.5, n.1, p.42-49, 1995.

Michel, B.E.; Kaufmann, M.R. The osmotic potential of polyethylene glycol 6000. Plant Physiology, Lancaster, v.51, n.5, p.914-916, 1973.

Moore, M.B.; Kidd, F.A. Seed source variation in induced moisture stress germination of ponderosa pines. Tree Planter's Notes, v.33, n.1, p.12-14, 1982.

Murray, G.A.; Swengen, J.B.; Beaver, G. Emergence of spring and summer-planted onions following osmotic priming. Hortscience, Alexandria, v.27, n.5, p.409-410, 1992.

Nassif, S.M.L.; Perez, S.C.J.G.A. Germinação de sementes de amendoim-do-campo (Pterogyne nitens Tul - FabaceaeCaesalpinoideae) submetidas a diferentes condições de estresses hídrico e salino. Revista Brasileira de Sementes, Brasília, v.19, n.2, p.143-150, 1997. 
Popinigis, F. Fisiologia da semente. Brasília: AGIPLAN, 1985. 285p.

Powell, A.A. Seed improvement by selection and invigoration. Scientia Agricola, Piracicaba, v.55, n.Esp., p.126-133, 1998.

Powell, A.A.; Mathews, S. The damaging effect of water on dry pea embryos during imbibition. Journal Experimental of Botany, Oxford, v.29, p.1215-1229, 1978.

Silva, L.M.M.; Aguiar, I.B.; Rodrigues, T.J.D. Seed germination of Bowdichia virgilioides Kunt, under water stress. Revista Brasileira de Engenharia Agrícola e Ambiental, Campina Grande, v.5, n.1, p.115-118, 2001.
Tambelini, M.; Perez, S.C.J.G.A. Efeito do estresse hídrico simulado com PEG (6000) ou manitol na germinação de sementes de barbatimão (Stryphnodendron polyphyllum Mart.). Revista Brasileira de Sementes, Brasília, v.20, n.1, p.226-232, 1998 .

Taylor, A.G.; Harman, G.E. Concepts and technologies of selected seed treatments. Annual Review Phytopathlogy, Palo Alto, v.28, p.321-339, 1990.

Trigo, M.F.O.O.; Nedel, J.L.; Lopes, N.F.; Trigo, L.F.N. Osmocondicionamento de sementes de cebola (Allium cepa L.) com soluções aeradas de polietilenoglicol. Revista Brasileira de Sementes, Brasília, v.21, n.1, p.145-150, 1999. 